\title{
A new emerging pandemic of severe fever with thrombocytopenia syndrome (SFTS)
}

\author{
Divya Sharma ${ }^{1} \cdot$ Mohit Kamthania $^{1}$
}

Received: 18 July 2020/ Accepted: 18 January 2021 / Published online: 29 April 2021

(C) Indian Virological Society 2021

\begin{abstract}
The aim of this study is to make aware every one of the deadliest diseases named severe fever with thrombocytopenia syndrome (SFTS). It has become the worldwide pandemic in recent few years. It is a kind of haemorrhagic fever, caused by SFTS virus (SFTSV), a novel phlebovirus of family Bunyaviridae. This syndrome is also a tick-borne zoonosis that means the virus transmitted from tick bite (having virus) into human body, i.e. infection spread from animals to humans and also transmitted from human to human. Epidemiological data of SFTS was collected to know the nature/symptoms of SFTSV. First case of this disease has been reported in China, followed by Japan, South korea, Taiwan, USA and many other countries. Vertebrates are the host of this disease and tick functions as a vector, where the virus can undergo brisk changes using gene mutation, homologous recombination and reassortments. The major symptoms of hemorrhagic fever are fever, thrombocytopenia, leucopenia and gastrointestinal abnormalities. Sometimes in very severe cases, full body organ failure may also take place and average death rate in humans is nearly $10 \%$. Old aged peoples are more prone to SFTSV infection. Apart from the fact of increasing SFTSV related health problems to humans, the pathogenesis of SFTS virus in human is not entirely understood and no treatment to this virus is still available. The simplest way to protect our self from this infection is to refrain from tick bite. Therefore, this disease has evolved to produce serious health issues to humans in various countries of world including china. This review
\end{abstract}

Divya Sharma

divya.biotech921@gmail.com

1 Department of Life Sciences, IAMR College, Ghaziabad, Uttar Pradesh, India discussing about causative agent, epidemiology, pathogenesis, diagnosis and treatment of SFTS. In order to control the spread of SFTSV, we have to stop the viral transmission or to protect the easily vulnerable population from tick bites, avoiding direct contact of infectious and also to use personal protective devices for SFTS patients. So, the weather conditions, mode of transmission and creation of new therapeutics like vaccines and drugs are the main areas of forthcoming research.

Keywords SFTS (SFTSV) - Tick bite · Phlebovirus · Hemorrhagic fever · Epidemiology · Pathogenesis

\section{Introduction}

During 2006-2007, various patients have been reported with the symptoms of having fever, stomach ache, gastrointestinal disorders, nausea, bloating, vomiting and thrombocytopenia in various regions of china [1,2]. The first human case of severe fever with thrombocytopenia syndrome (SFTS), was also found in shaanxi province of western china and the patient was 66 years old man with high fever, chills, pharyngeal pain, nausea and vomiting [3]. The causative agent of this disease is SFTS virus, which was identified as a phlebovirus of family Bunyaviridae. In the initial days, it was suspected that this disease caused by Anaplasma phagocytophilum bacterium, but the pathogen was not isolated from the patients, till the isolation of SFTSV from the blood of human granulocytic anaplasmosis patient in 2009 from henan province. Like other phleoviruses, genome of SFTSV also consist of large, medium and small segments. Two non-overlapping open reading frames (ORFs) of small segment are encoding the nucleocapsid and non-structural proteins. The medium and 
large segments encode the RNA-dependent RNA polymerase and Gn-Gc envelope glycoproteins, respectively [4]. After complete sequencing of SFTSV, it shows close resemblance with Uukuniemi virus and sequences can also be found in GenBank. The infection is transmitted from infected tick and viral sequences obtained from these ticks on animal are closely related to those collected from human (zoonotic transmission) [5], but various reports are also available showing human to human transmission of infection [6-8]. In china, during 2013 to 2016, total 7419 cases of human have been confirmed with 355 deaths [9], SFTS has been also found in Henan, Hubei, Anhui, Shandong, Jiangsu, Zhejiang, Liaoning, Yunnan, Guangxi, Jiangxi and Shannxi [10]. After an epidemiological survey, SFTS have been also reported in Japan [11, 12], South Korea [13-15], USA [16] and Taiwan [9, 17]. So, due to the worldwide spread of SFTSV, high mortality rate and human communicable nature of virus, it poses a great menace globally.

Besides from the fact of increasing SFTSV related health problems to humans, the pathogenesis of SFTS virus in human is not entirely understood and no treatment to this virus is still available. The simple way to protect our self from this infection is to refrain from tick bite. Therefore, this disease has evolved to produce serious health issues to humans in various countries of world including china. All review articles available in literature are deficient in clinical, epidemiological and research related description of SFTS [18-20, 9]. So, this review is the systematic presentation of SFTS cases, SFTSV and detailed summary of research. This review discussing about causative agent, epidemiology, pathogenesis, diagnosis and treatment of SFTS.

\section{Causative agent and genome Organization}

The causative agent of SFTS is a virus known as SFTSV, which is a single-stranded negative sense RNA and comprises of three segments i.e., small, medium and large (S, M, L) with nucleotides sequences of 1744, 3378 and 6368 respectively [9]. In Table 1 we have presented that the $\mathrm{L}$ segment is encoded by RNA-dependent RNA polymerase (RdRp) with 2084 amino acids, M segment encoded by 1073 amino acids glycoprotein (Gn and Gc) and S segment encoding the non-structural protein (29-910 nucleotides) in the sense orientation and the nucleoprotein (1702 - 965 nucleotides) in the antisense orientation with intergenic region of 54-base pairs respectively. These segments are covered with untranslated regions (UTRs) just like other bunyaviruses, which are short and highly conserved. For example, SFTSV strain HB29 with GenBank accession number: $\mathrm{NC}-018136, \quad \mathrm{NC}-018138$ and $\mathrm{NC}-018137$ ) contains L, $\mathrm{M}$ and $\mathrm{S}$ segments with 16,18 and 42 nucleotides at $5^{\prime}$ terminus and 100, 141 and 28 nucleotides at $3^{\prime}$ terminus respectively. Untranslated regions (UTRs) of these segments present at $5^{\prime}$ and $3^{\prime}$ terminus is highly complementary, which separates the viral RNAs from nonviral RNAs, and play crucial role in transcription, viral RNA replication, viral RNA encapsidation, and viral genome packaging respectively [19]. The genomic study of SFTSV revealed that there is only $38.3 \%$ homologus sequences present in SFTSV, which are similar to other bunyaviruses. Bunyaviruses are RNA viruses with five generic groups such as orthobunyaviruses (three sequences AMLq13, AMLq14 and AMLq16 with Gene Bank accession HM107840, HM107841 and HM107842 respectively showed similarities with OROV TRVL9760 (AF64531) and to the strain BeAn19991 (AF164532), nairoviruses, tospoviruses (GenBank accession numbers KC261947 to KC261976), phleboviruses (GenBank accession numbers HM119401 to HM119436 and HM466934 to HM466936) and hantaviruses [18]. Bunaviridae are only transferred by arthropod vectors [21] and can infect the animals, plants [22] and humans. Phleboviruses are classified into two groups with 70 antigenically different serotypes, phlebotomus fever transmitted by phlebotominae sandflies or mosquitoes and Uukuniemi fever by ticks [23]. Genetically, SFTSV are placed under phlebovirus, but they represent a third unique group due to some different characters [4]. SFTSV and heartland virus shows some sequence similarity with Uukuniemi group, so they are placed under that group. This group does not have middle segment (nonstructural proteins), have some serological features and ticks as common arthropod vector [24, 25]. Various symptoms of this disease, worldwide study of epidemiology and SFTS testing in laboratory, all these shows an etiological relationship among SFTS and SFTSV. So, these viruses are appearing as the potent pathogen of human health, due to the increased cases in new hosts worldwide.

\section{Epidemiology}

First case of SFTS was described in Henan and Hubei provinces of China in the middle of March-July, 2009 mentioned by National Health and Family Planning Commissio [26], but the first case occurred in Dingyuan County, Chuzhou, Anhui province in September, 2006 [7]. Total 171 patients of SFTS are observed from June, 2009 to September, 2010 in Henan, Hubei, Shandong, Liaoning, Anhui, and Jiangsu provinces provinces [2]. Towards the end of 2012, SFTSV infection has been spread into another 11 provinces such as Henan, Hubei, Anhui, Shandong, Jiangsu, Zhejiang, Jiangxi, Guangxi, Yunnan, Shaanxi, and 
Table 1 Genomic properties of SFTSV

\begin{tabular}{|c|c|c|c|c|c|c|}
\hline Segments & $\begin{array}{l}\text { Size } \\
(\mathrm{bp})\end{array}$ & $\begin{array}{l}\text { ORF } \\
\text { (open } \\
\text { reading } \\
\text { frames) }\end{array}$ & Position & Direction & Proteins & Functions \\
\hline Large & 6368 & 1 & $17-6271$ & $5^{\prime}-3^{\prime}$ & $\begin{array}{l}\text { RNA dependent } \\
\text { RNA polymerase } \\
\text { (RdRp) }\end{array}$ & Replication and transcription \\
\hline \multirow[t]{3}{*}{ Medium } & 3378 & 2 & $19-1704$ & $5^{\prime}-3^{\prime}$ & Glycoprotein Gn & Helps in assembly and formation of virus \\
\hline & & & $1705-3240$ & $5^{\prime}-3^{\prime}$ & Glycoprotein Gs & $\begin{array}{l}\text { Have immunogenic, neutralizing epitopes and important for } \\
\text { virus infection }\end{array}$ \\
\hline & & & $29-910$ & $5^{\prime}-3^{\prime}$ & $\begin{array}{l}\text { Non-structural } \\
\text { proteins (NSs) }\end{array}$ & Regulates host immune response, viral replication \\
\hline Small & 1744 & 2 & $1702-965$ & $3^{\prime}-5^{\prime}$ & $\begin{array}{l}\text { Nucleocapsid protein } \\
\text { (NP) }\end{array}$ & $\begin{array}{l}\text { Viral replication, transcription, forms intracellular inclusion } \\
\text { bodies, packages genomic RNA into ribonucleoproteins }\end{array}$ \\
\hline
\end{tabular}

Liaoning. In between 2011 and 12, around 2047 cases has been reported in China including 129 deaths from 206 counties of eastern and central China. Most of the cases are from rural areas like mountainous or hilly areas [27]. The serological surveillance has reported that $1.0-3.8 \%$ population of hilly regions have SFTSV antibodies, which suggested the widely spread nature of SFTSV in china [18]. First case of SFTS in North Korea was reported in 2009 [28] and fatal case was also observed in South Korea in 2012 [13], along with six more cases with four deaths in 2013 [29]. Eleven cases with seven deaths have been also reported from Japan, in April, 2013 [30]. In USA the disease was firstly noticed in 2009, when two farmers with high fever, fatigue, diarrhoea, thrombocytopenia and leucopenia are admitted in hospitals of northwestern Missouri due to the bite of ticks [16]. Till now, there is no case of SFTSV infection in animals, but the blood from infected animals can be a potent source of infection [31]. So, animal doctors and slaughter house workers are at higher risk risk [32]. Total number of SFTS patients reported during 2013-2018, in South Korea, Japan and China (National Centre for Infectious Diseases) has been presented in Table 2 [33-36].

\section{Virus structure, mechanism and pathogenesis}

Virions of SFTSV are spherical and enclosed with a membrane of polypeptide spikes 5-10 nm long. SFTSV lacks protein layer, which makes the bunyaviruses flexible. Ribonucleoprotein complexes (RNPs) provides packaging to viral RNAs, each complex contains viral RNA, which is enveloped by viral protein $\mathrm{N}$ and the RNPs of bunyaviruses often forms closed, circular-shaped loosely coiled structures. RNA-dependent RNA polymerase (RdRp) of virus is also connected with RNP and forms threadlike structures. SFTSV N protein forms crystal ring-shaped hexameric structures to complete the process of RNA encapsidation and RNA binding. After infection of host cells by SFTSV, virus propagates inside the cytoplasm of host cell and the secretion of RNPs from SFTSV initiates the transcription catalysed by viral RdRp. Viral RNA replication assisted by protein synthesis leads to the production of complementary RNAs (cRNAs) and viral RNAs (vRNAs). All three segments (S, M and L) vary in replication i.e., $\mathrm{M}>\mathrm{L}>\mathrm{S}$. Then, the synthesized cRNAs and vRNAs gets packaged in RNP due to the interaction of viral protein $\mathrm{N}$ and RdRp. This newly formed RNPs are used for the synthesis of viral mRNA and protein [19]. The aetiology of SFTSV is not thoroughly understood, but according to the pathogenicity of bunyaviruses, SFTSV prevent the immune response of the host, which can be seen by intense virus replication along with failure of multiple organs. After examining the SFTSV patients, it was observed that CD3-positive and CD4-positive T lymphocytes, which contributes in the immune functioning are low in number than their normal concentration and amount of natural killer cells are increased mainly in acute phase and grievous SFTSV infection [37]. The inhibition of immune function favours the increase of secondary infection by provoking patient's health status. Immunoregulatory functions have been performed by natural killer cells by producing various cytokines, such as interferon $\gamma$, tumour necrosis factor (TNF) $\alpha$, interleukin 10 and granulocyte colony-stimulating factors (G-CSF). The amount of these cytokines is proportional to the severity of disease. Inflammatory cytokines also help in pathogenesis of viral diseases and some proinflammatory cytokines expresses at abnormal rate in cytokine pool, which shows the severe 
Table 2 Total number of SFTS patients reported during 2013-2018, in South Korea, Japan and China (National Centre for Infectious Diseases)

\begin{tabular}{|c|c|c|c|c|c|c|c|}
\hline \multirow[t]{2}{*}{ Year } & \multicolumn{2}{|l|}{ South Korea } & \multicolumn{2}{|l|}{ Japan } & \multicolumn{2}{|l|}{ China } & \multirow[t]{2}{*}{ Common symptoms } \\
\hline & Total cases & Death & Total cases & Death & Total cases & Death & \\
\hline 2013 & 36 & 17 & 40 & 14 & 676 & 48 & Severe fever \\
\hline 2014 & 55 & 18 & 61 & 16 & 1034 & 81 & Gastrointestinal \\
\hline 2015 & 81 & 21 & 60 & 11 & 1304 & 68 & Thrombocytopaenia \\
\hline 2016 & 166 & 19 & 60 & 8 & 1306 & 57 & leukopenia \\
\hline 2017 & 271 & 54 & 89 & 7 & NA & NA & Increased liver enzymes \\
\hline 2018 & 259 & 0 & 0 & 0 & NA & NA & Myalgia \\
\hline References & \multicolumn{2}{|c|}{$\begin{array}{l}\text { Kim et al. (2019), Maslow } \\
\text { et al. (2019) }\end{array}$} & \multicolumn{2}{|c|}{$\begin{array}{l}\text { Kobayashi et al. } \\
(2020)\end{array}$} & \multicolumn{2}{|c|}{$\begin{array}{l}\text { National Centre for Infectious Diseases } \\
\text { (Updated on June 2020) }\end{array}$} & Anorexia \\
\hline Vector & \multicolumn{2}{|l|}{ Tick borne } & \multicolumn{2}{|c|}{$\begin{array}{l}\text { Body fluids of ill } \\
\text { animals }\end{array}$} & \multicolumn{2}{|c|}{ Ticks and Person to person transmission } & Fatigue \\
\hline Age groups & \multicolumn{6}{|c|}{5 to 87 years (Median 61 years) } & Chill \\
\hline
\end{tabular}

form of SFTS [38]. Innate immune system provide protection against virus by producing interferon $\beta$, but patients with SFTS lacks interferon $\beta$. All the transcription factors related to interferon $\beta$ are upregulated moderately in SFTSV-infected monocytes, whereas upstreaming molecules like TNF-receptor-associated factors 3, 6 and antiviral signalling protein of mitochondria are either remains unaltered or decreased, which further inhibits the induction of interferon $\beta$ [39]. Three different patterns have been shown by the unbalanced cytokines such as expression of interleukins 6 and 10, interleukin-1 receptor antagonist, G-CSF, interferon- $\gamma$-inducible protein and monocyte chemotactic protein 1 is increased in more fatal cases of SFTS, than in nonfatal cases. Whereas PDGF (platelet-derived growth factor) and RANTES (regulated on activation and normally T-cell expressed) expression is low. During the convalescent phase all these cytokines returns to their normal values. The expression of interleukins $1 \beta$ and 8 and inflammatory proteins $1 \alpha$ and $1 \beta$ of macrophage is also increased only in fatal cases as well as in convalescent phase of survivors [40]. These cytokines have play important role in virus load in serum and other associated clinical characteristics like monocyte chemotactic protein 1 and interleukin 8 are crucial in progressive kidney injury [41], interleukin-1 receptor antagonist and interleukin 6 are associated with severe form of nephropathia epidemica [42], monocyte chemotactic protein 1 and interferon- $\gamma$-inducible protein produces inflammation of liver along with fibrosis [43], interleukin 8 have the capability to raise the permeability of capillaries [44]. Reduced level expression of RANTES associated with viral disease severity [45] and together with platelet-derived growth factor in SFTS patients is due to low number of platelets circulating in the blood [46]. Symptoms of fever in SFTS patients are associated with increased TNFa, which further work on endothelium, promotes vasodilating substances, nitric oxide synthase and increasing vascular permeability [47]. Virus of SFTS attached to platelets, these are identified and eliminated by macrophages circulating in the spleen, which causes thrombocytopenia [48]. The major cells, where SFTSV can replicate is reticular cells, but can also multiply in other cells [18]. As SFTSV targets the multiple organs resulted in multiple organ failure. So, starting from acute phase having febrile illness, turns into multiple organ failure (severe form) and further leads to the death of patient (fatal form). SFTSV infects the B-cells lymphocytes, multiple lymphoid or nonlymphoid organs, such as blood, spleen, the liver, adrenal glands, intestine, heart, lungs, and kidneys in fatal human SFTS cases [49].

\section{Diagnosis}

In the beginning the critical investigation of SFTSV is depends on various symptoms shown by patient and their clinical testing like fever, thrombocytopenia and elevated levels of liver enzymes. The interpretation of these disease symptoms is important for the patient's survival and to stop the further spreading of the disease. Epidemiological features also help in diagnosis and these includes geographical location, history of tick bite, living or working environments and epidemic seasons [50,18], but as the symptoms of SFTS are not specific in every case, so to make them authentic their consent from laboratory is necessary. Sometimes multiple tests have to be conducted to diagnose SFTS haemorrhagic fever along with renal syndrome, dengue fever, thrombocytopenia purpura, typhoid, 
leptospirosis, and human anaplasmosis [48]. Detailed confirmation of SFTSV disease needs anyone of mentioned prerequisite such as isolation of SFTSV from various sample of the patient and RNA or antibodies detection of SFTSV from the blood or serum of patient [51]. Isolation of virus can become the full proof of SFTSV infection and this virus affect only CPE on DH82 cells not on the Vero cells or Vero E6 cells in primary isolation, this may be the cause that's why isolation of SFTSV was failed in China $[4,50]$. For the isolation of virus only biosafety level-3 labs should be used as suggested by National Health and Family Planning Commission [26]. The procedure of virus isolation although simple and requires $2-5$ days, but there is either low or no cytopathic effect in virus, so electron microscope and molecular or serological protocols are required [2, 4, 52].

Isolation of virus is the commonly employed method in research institutions, but this takes lots of time, however remaining two methods are frequently used for clinical confirmation. Acute phase serum from patients after the two weeks of the disease can be used for the detection of viral RNA [51]. Amplification of viral nucleic acid (RNA) have been done using reverse transcription-PCR (RTPCR), real-time PCR, reverse transcription loop-mediated isothermal amplification (RT-LAMP) and RT cross-priming amplification amplification [53, 54]. All these amplification techniques work on the same principle i.e., extraction of viral RNA, reverse transcription and DNA amplification. Reverse transcription (RT) PCR method is very conspicuous, sentient and intense for presumptive laboratory diagnosis of SFTSV infection. Improvement in Reverse transcription (RT) PCR generated Automated RTPCR, which is contamination free and have high specificity or sensitivity than conventional RT-PCR $[53,55]$. On the other hand, real-time PCR is also specific and sensitive in nature, but RT-LAMP is very ingenious and inexpensive. In reality, the efficiency of amplification targets the distinct portions of SFTSV varies, but amplification target the S segment is very sensitive RT-PCR assay [56]. Multiplex real-time (RT) PCR can easily explore the SFTSV, hantaan virus, seoul virus and dengue virus [57]. Reverse transcription loop-mediated isothermal amplification (RTLAMP) and RT cross-priming amplification are the types of isothermal amplification methods and have been designed to diagnose SFTSV RNA. Currently, for the rapid detection of SFTSV, RT-cross-priming amplification (RTCPA) combined with vertical-flow visualization strip has been developed, which is very easy, instrument free and practicable in point-of-care testing [58]. Even though SFTSV infection produces high viral titre, which assist the isolation of virus and ascertain it at molecular level, but time period is very less usually 1-6 days after the onset of infection. Special antibodies related to SFTSV are IgG and
$\operatorname{IgM}$, which can be detected even after 7 days of disease onset. IgG and IgM can be detected up to 5 years and 4 months respectively, after infection as described by National Health and Family Planning Commission [26]. Various serological assays like serum neutralisation test, indirect immunofluorescence assay, double antigen sandwich ELISA, in-house mac-ELISA and indirect ELISA are used to detect SFTSV related antibodies from serum samples. To detect the virus specific antibodies indirect immune-fluorescence assay is also used, which confirm the onset and examination of viral infection [3, 59]. Neutralisation test is just like the standard gold, but this test is costly, laborious, need biosafety labs and most prominently requires modifications in live virus. ELISA assays are cheap, less time requiring and recombinant nucleoproteinbased double-antigen sandwich ELISA has been used for the detection of SFTSV antibodies in people and animals. This is more sensitive than neutralisation test (no crossreaction between SFTSV and dengue virus or hantavirus was found) [60].

\section{Treatment}

Currently, no treatment or vaccines are available for SFSTSV disease. Other backup treatments such as plasma, platelet, granulocyte colony stimulating factor (GCSF), recombinant human interleukin 11 and gamma globulin are the important segment of case treatment [61]. At the same time, some precautions need to be taken in order to protect water, balance of electrolytes and treatment of complications is necessary. For the treatment of Crimean-Congo Haemorrhagic Fever (CCHF) infections and haemorrhagic fever with renal syndrome, Ribavirin has been found to be effective, but due to insufficient data it is not appreciable to apply this medication for the treatment of SFTS patients [62]. For the treatment of SFTS patients with acute lung injury and acute respiratory distress syndrome (ALI/ ARDS) use of corticosteroids is under dispute, due to the suppression of cytokine storm and multiple cytokines produced in acute phase of SFTSV infection are also associated with severe form of infection. Antibodies also play important role in the treatment of several viral infections including Hantaan virus [63], cytomegalovirus [64] and rabies virus [65] by using various mechanisms like neutralisation, complement activation, antibody-dependent cellular cytotoxicity and opsonisation [66]. Neutralising antibodies has tendency to lowers viral load, transmission, which further decrease the chances of getting severe form of disease. Similarly, human monoclonal antibody $4-5$, isolated from phage antibody library have neutralising action for SFTSV in laboratory and can be used to prevent the spreading of disease to other peoples, 
who are at high risk like staff of hospital and patient's relatives [67].

\section{Conclusions}

SFTS is a severe form of disease emerging as worldwide pandemic including China, Japan, South Korea, USA and Taiwan along with the main epidemic region i.e., Central China. Due to the very fast changes in SFTSV using gene mutation, reassortment and recombination in tick vectors and animal hosts, it poses a great threat to the health of world's population. The current research about the vaccination and epidemiology should need to be refined to understand the pandemic globally, as only the identification and diagnosis of SFTS related virus has been done in the last few years. At present, the major approaches to control the SFTSV are either to stop the viral transmission or to protect the easily vulnerable population from tick bites, avoiding direct contact of infection and also to use personal protective devices for SFTS patients. So, the weather conditions, mode of transmission and creation of new therapeutics like vaccines and drugs are the main areas of forthcoming research.

Acknowledgements The authors gratefully acknowledge the IAMR (Institute of Applied Medicines and Research) college, Ghaziabad, Uttar Pradesh for supporting the research.

Authors' contributions All authors contributed to the final reviews of the manuscript. All authors read and approved the final manuscript.

Funding Not applicable.

\section{Compliance with ethical standards}

Conflict of interest The author declares that there is no conflict of interest.

\section{References}

1. Zhang L, Liu Y, Ni D, Li Q, Yu Y, Yu XJ, et al. Nosocomial transmission of human granulocytic anaplasmosis in China. JAMA. 2008;300:2263-70.

2. Xu B, Liu L, Huang X, et al. Metagenomic analysis of fever, thrombocytopenia and leukopenia syndrome (FTLS) in Henan Province, China: discovery of a new bunyavirus. Plos Pathog. 2011;7(11):e1002369.

3. Wei J, Li S, Dong J, Tian H, Chowell G, Tian H, et al. The first human infection with severe fever with thrombocytopenia syndrome virus in Shaanxi Province, China. Int $\mathbf{J}$ Infect Dis. 2015;35:37-9.

4. Yu XJ, Liang MF, Zhang SY, Liu Y, et al. Fever with thrombocytopenia associated with a novel bunyavirus in China. N Engl J Med. 2011;364:1523-32.
5. Zhang YZ, Zhou DJ, Qin XC, Tian JH, Xiong Y, Wang JB, Chen $\mathrm{XP}$, et al. The ecology, genetic diversity, and phylogeny of Huaiyangshan virus in China. J Virol. 2012;86:2864-8.

6. Bao CJ, Guo XL, Qi X, Hu JL, Zhou MH, Varma JK, Cui LB, et al. A family cluster of infections by a newly recognized bunyavirus in eastern China, 2007: further evidence of person-toperson transmission. Clin Infect Dis. 2011;3:1208-14.

7. Liu Y, Li Q, Hu W, Wu J, Wang Y, Mei L, Walker DH, et al. Person-to-person transmission of severe fever with thrombocytopenia syndrome virus. Vector Borne Zoonotic Dis. 2012;12:156-60.

8. Jiang XL, Zhang S, Jiang M, Bi ZQ, Liang MF, Ding SJ, Wang $\mathrm{SW}$, et al. A cluster of person-to-person transmission cases caused by SFTS virus in Penglai, China. Clin Microbiol Infect. 2015;21:274-9. https://doi.org/10.1016/j.cmi.2014.10.006.

9. Zhan J, Wang Q, Cheng J, et al. Current status of severe fever with thrombocytopenia syndrome in China. Virol Sin. 2017;32(1):51-62. https://doi.org/10.1007/s12250-016-3931-1.

10. Lam T, Liu W, Bowden TA, Cui N, Zhuang L, Liu K, Zhang Y, Cao W, Pybus OG. Evolutionary and molecular analysis of the emergent severe fever with thrombocytopenia syndrome virus. Epidemic. 2013;5:1-10.

11. Takahashi T, Maeda K, Suzuki T, et al. The first identification and retrospective study of severe Fever with thrombocytopenia syndrome in Japan. J Infect Dis. 2014;209:816-27.

12. Hayasaka D, Fuxun Y, Yoshikawa A, Posadas-Herrera G, Shimada S, et al. Seroepidemiological evidence of severe fever with thrombocytopenia syndrome virus infections in wild boars in Nagasaki, Japan. Trop Med Health. 2016;44:6.

13. Kim KH, Yi J, Kim G, et al. Severe fever with thrombocytopenia syndrome, South Korea, 2012. Emerg Infect Dis. 2013;19:1892-4.

14. Kim KH, Ko MK. Seroprevalence of Severe Fever with Thrombocytopenia Syndrome in Southeastern Korea. J Korean Med Sci. 2017;32:29-32.

15. Yun SM, Lee WG, Ryou J, Yang SC, Park SW, et al. Severe fever with thrombocytopenia syndrome virus in ticks collected from humans, South Korea 2013. Emerg Infect Dis. 2014;20:1358-61.

16. Mcmullan LK, Folk SM, Kelly AJ, et al. A new phlebovirus associated with severe febrile illness in Missouri. N Engl J Med. 2012;367:834-41.

17. Lin T-L, Ou S-C, Maeda K, Shimoda H, Chan JP-W, Tu W-C, Hsu W-L, et al. The first discovery of severe fever with thrombocytopenia syndrome virus in Taiwan. Emerg Microbes Infect. 2020;9(1):148-51. https://doi.org/10.1080/22221751.2019. 1710436 .

18. Liu Q, Biao H, Si-Yang H, Feng W, Xing-Quan Z, et al. Severe fever with thrombocytopenia syndrome, an emerging tick-borne zoonosis. Lancet Infect Dis. 2014;14:763-72.

19. Lei X-P, Liu M, Yu X. Severe fever with thrombocytopenia syndrome and its pathogen SFTSV. Microbes Infect. 2015;17:149-54.

20. Silvas J, Aguilar P. The Emergence of Severe Fever with Thrombocytopenia Syndrome Virus Am. J Trop Med Hyg. 2015;97(4):992-6.

21. Walter CT, Barr JN. Recent advances in the molecular and cellular biology of bunyaviruses. J Gen Virol. 2011;92:2467-84.

22. Li JL, Ling JX, Liu DY, et al. Genetic characterization of a new subtype of Hantaan virus isolated from a hemorrhagic fever with renal syndrome (HFRS) epidemic area in Hubei Province, China. Arch Virol. 2012;157:1981-7.

23. Bishop DH, Calisher $\mathrm{CH}$, Casals J, et al. Bunyaviridae Intervirol. 1980;14:125-43.

24. Palacios G, Savji N, Travassos DRA, et al. Characterization of the Uukuniemi virus group (Phlebovirus: Bunyaviridae): evidence for seven distinct species. J Virol. 2013;87:3187-95. 
25. Matsuno K, Weisend C, Travassos DRAP, et al. Characterization of the Bhanja serogroup viruses (Bunyaviridae): a novel species of the genus Phlebovirus and its relationship with other emerging tick-borne phleboviruses. J Virol. 2013;87:3719-28.

26. National Health and Family Planning Commission of the People's Replublic China. Guide for severe fever with thrombocytopenia syndrome control (2010 edit). http://www.moh.gov.cn/ mohwsyjbgs/s8348/201010/49272.html. Accessed 23 Sept 2013 (in Chinese).

27. Li Y, Zhou H, Mu D, Yin W, Yu H. Epidemiological analysis on severe fever with thrombocytopenia syndrome under the national surveillance data from 2011 to 2014, China. Zhonghua liu xing bing xue za zhi. 2015;36:598-602.

28. Denic S, Janbeih J, Nair S, Conca W, Tariq WU, Al-Salam S. Acute thrombocytopenia, leucopenia, and multiorgan dysfunction: the first case of SFTS Bunyavirus outside China? Case Rep Infect Dis. 2011: 204056.

29. South Korea. Four die from tickborne severe fever with thrombocytopenia syndrome (SFTS). http://blogs.uw.edu/apecein/ 2013/06/07/south-korea-four-die-from-tickborne-severe-fever with-thrombocytopenia-syndrome-sfts/. Accessed Sept 2013 (2013).

30. ProMEDmail. Severe fever with thrombocytopenia syndromeJapan (05): update. Apr 10. 2013. http://www.promedmail.org/ direct.php?id=20130410.636456. Accessed Sep 2013.

31. Cui F, Cao HX, Wang L, et al. Clinical and epidemiological study on severe fever with thrombocytopenia syndrome in Yiyuan County, Shandong Province, China. Am J Trop Med Hyg. 2013;88:510-2

32. Liang S, Bao C, Zhou M, et al. Seroprevalence and risk factors for severe Fever with thrombocytopenia syndrome virus infection in jiangsu province, china, 2011. Am J Trop Med Hyg. 2014;90:256-9.

33. National Centre for Infectious Diseases. (updated on June 2020) https://www.ncid.sg/Health-Professionals/Joint-MOH-NCID-Gui dances/Pages/Severe-Fever-with-Thrombocytopenia-Syndrome. aspx.

34. Kim J, Bae J. Epidemiological and clinical characteristics of confirmed cases of severe fever with thrombocytopenia syndrome in jeju province, korea, 2014-2018. J Prev Med Public Health. 2019;52:195-9.

35. Maslow JN, Kwon JJ, Mikota SK, Spruill S, et al. Severe fever and thrombocytopenia syndrome virus infection: Considerations for vaccine evaluation of a rare disease. Hum Vaccin Immunother. 2019;15(10):2249-57.

36. Kobayashi Y, Kato H, Yamagishi T, Shimada T, et al. Severe fever with thrombocytopenia syndrome, Japan, 2013-2017. Emerg Infect Dis. 2020;26(4):692-9.

37. Sun $\mathrm{L}, \mathrm{Hu}$ Y, Niyonsaba A, et al. Detection and evaluation of immunofunction of patients with severe fever with thrombocytopenia syndrome. Clin Exp Med. 2013. https://doi.org/10.1007/ s10238-013-0259-0.

38. Deng B, Zhang S, Geng Y, et al. Cytokine and chemokine levels in patients with severe fever with thrombocytopenia syndrome virus. Plos One. 2012;7:41365.

39. Qu B, Qi X, Wu X, et al. Suppression of the interferon and NF$\kappa \mathrm{B}$ responses by severe fever with thrombocytopenia syndrome virus. J Virol. 2012;86:8388-401.

40. Sun Y, Jin C, Zhan F, et al. Host cytokine storm is associated with disease severity of severe fever with thrombocytopenia syndrome. J Infect Dis. 2012;206:1085-94.

41. Zoja C, Garcia PB, Remuzzi G. The role of chemokines in progressive renal disease. Front Biosci (Landmark Ed). 2009; 14:1815-22.

42. Temonen M, Mustonen J, Helin H, Pasternack A, Vaheri A, Holthofer H. Cytokines, adhesion molecules and cellular infi ltration in nephropathia epidemica kidneys: an immunohistochemical study. Clin Immunol Immunopathol. 1996;78:47-55.

43. Wasmuth HE, Tacke F, Trautwein C. Chemokines in liver infl ammation and fibrosis. Semin Liver Dis. 2010;30:215-25.

44. Petreaca ML, Yao M, Liu Y, Defea K, Martins-Green M. Transactivation of vascular endothelial growth factor receptor-2 by interleukin-8 (IL-8/CXCL8) is required for IL-8/CXCL8-induced endothelial permeability. Mol Biol Cell. 2007;18:5014-23.

45. Repeke CE, Ferreira SJ, Vieira AE, et al. Dose-response metRANTES treatment of experimental periodontitis: a narrow edge between the disease severity attenuation and infection control. Plos One. 2011;6:e22526.

46. Ellis M, al-Ramadi B, Hedstrom U, Frampton C, Alizadeh H, Kristensen J. Significance of the CC chemokine RANTES in patients with haematological malignancy: results from a prospective observational study. Br J Haematol. 2005;128:482-9.

47. Seynhaeve ALB, Vermeulen CE, Eggermont AMM, Hagen TLMT. Cytokines and vascular permeability: an in vitro study on human endothelial cells in relation to tumor necrosis factor-alpha-primed peripheral blood mononuclear cells. Cell Biochem Biophys. 2006;44:157-69.

48. Jin C, Liang M, Ning J, et al. Pathogenesis of emerging severe fever with thrombocytopenia syndrome virus in C57/BL6 mouse model. Proc Natl Acad Sci USA. 2012;109:10053-8.

49. Suzuki T, Sato Y, Sano K, Arashiro T, Katano H, Nakajima N, Morikawa $\mathrm{S}$, et al. Severe fever with thrombocytopenia syndrome virus targets B cells in lethal human infections. J Clin Investig. 2020;130(2):799-812.

50. Zhang X, Liu Y, Zhao L, Li B, Yu H, Wen H, et al. An emerging hemorrhagic fever in China caused by a novel bunyavirus SFTSV. Sci China Life Sci. 2013;56(8):697-700.

51. Li D. A highly pathogenic new bunyavirus emerged in China. Emerg Microbes Infect. 2013;2(1):1.

52. Goldsmith CS, Ksiazek TG, Rollin PE, et al. Cell culture and electron microscopy for identifying viruses in diseases of unknown cause. Emerg Infect Dis. 2013;19:886-91.

53. Sun Y, Liang M, Qu J, Jin C, Zhang Q, Li J, et al. Early diagnosis of novel SFTS bunyavirus infection by quantitative real-time RTPCR assay. J Clin Virol. 2012;53(1):48-53.

54. Yang G, Li B, Liu L, Huang W, Zhang W, Liu Y, et al. Development and evaluation of a reverse transcription loop-mediated isothermal amplification assay for rapid detection of a new SFTS bunyavirus. Arch Virol. 2012;157(9):1779-83.

55. Li Z, Cui L, Zhou M, et al. Development and application of a one-step real-time RT-PCR using a minor-groove-binding probe for the detection of a novel bunyavirus in clinical specimens. J Med Virol. 2013;85:370-7.

56. Chi YY, Zhai SY, Wen HL, Cui F, Song YY, Wang L, et al. SFTSV RNA detection in seropositive patients. J Shandong Univ (Health Sci). 2012;50:118-21.

57. Li Z, Qi X, Zhou M, et al. A two-tube multiplex real-time RTPCR assay for the detection of four hemorrhagic fever viruses: severe fever with thrombocytopenia syndrome virus, Hantaan virus, Seoul virus, and dengue virus. Arch Virol. 2013;158:1857-63.

58. Cui L, Ge Y, Qi X, Xu G, Li H, Zhao K, et al. Detection of severe fever with thrombocytopenia syndrome virus by reverse transcription-crosspriming amplification coupled with vertical flow visualization. J Clin Microbiol. 2012;50(12):3881-5.

59. Wu X, Qi X, Qu B, Zhang Z, Liang M, Li C, et al. Evasion of antiviral immunity through sequestering TBK1/IKKe/IRF3 into viral inclusion bodies. J Virol. 2014;88(6):3067-76.

60. Jiao Y, Zeng X, Guo X, et al. Preparation and evaluation of recombinant severe fever with thrombocytopenia syndrome virus nucleocapsid protein for detection of total antibodies in human 
and animal sera by double-antigen sandwich enzyme-linked immunosorbent assay. J Clin Microbiol. 2012;50:372-7.

61. Kim UJ, Kim DM, Ahn JH, Kang SJ, Jang HC, et al. Successful treatment of rapidly progressing severe fever with thrombocytopenia syndrome with neurological complications using intravenous immunoglobulin and corticosteroid. Antivir Ther. 2016;21:637-40.

62. Liu W, Lu QB, Cui N, Li H, Wang LY, et al. Case-fatality ratio and effectiveness of ribavirin therapy among hospitalized patients in china who had severe fever with thrombocytopenia syndrome. Clin Infect Dis. 2013;57:1292-9.

63. Xu R, Yang XY, Yang DF, Zou CY, Gong PL, Zeng FD. Phase I evaluation of the safety and pharmacokinetics of a single-dose intravenous injection of a murine monoclonal antibody against Hantaan virus in healthy volunteers. Antimicrob Agents Chemother. 2009;53:5055-9.

64. Winston DJ, Ho WG, Lin CH, et al. Intravenous immune globulin for prevention of cytomegalovirus infection and interstitial pneumonia after bone marrow transplantation. Ann Intern Med. 1987;106:12-8.

65. Lang J, Gravenstein S, Briggs D, et al. Evaluation of the safety and immunogenicity of a new, heat-treated human rabies immune globulin using a sham, post-exposure prophylaxis of rabies. Biologicals. 1998;26:7-15.

66. Casadevall A, Dadachova E, Pirofski LA. Passive antibody therapy for infectious diseases. Nat Rev Microbiol. 2004;2:695-703.

67. Guo X, Zhang L, Zhang W, et al. Human antibody neutralizes severe Fever with thrombocytopenia syndrome virus, an emerging hemorrhagic Fever virus. Clin Vaccine Immunol. 2013;20:1426-32.

\section{Publisher's note}

Springer Nature remains neutral with regard to jurisdictional claims in published maps and institutional affiliations. 